Article

\title{
The Influence of AlN Intermediate Layer on the Structural and Chemical Properties of SiC Thin Films Produced by High-Power Impulse Magnetron Sputtering
}

\author{
Nierlly Galvão ${ }^{1, *}$, Marciel Guerino ${ }^{1}$, Tiago Campos ${ }^{1}$, Korneli Grigorov ${ }^{2}$, Mariana Fraga ${ }^{3, *(1)}$, \\ Bruno Rodrigues ${ }^{1,4}$, Rodrigo Pessoa ${ }^{1,4}$, Julien Camus ${ }^{5}$, Mohammed Djouadi ${ }^{5}$ and \\ Homero Maciel ${ }^{1,4}$ \\ 1 Centro de Ciência e Tecnologia de Plasmas e Materiais-PlasMat, Instituto Tecnológico de Aeronáutica, \\ São José dos Campos 12228-900, SP, Brazil; marcielguerino@yahoo.com.br (M.G.); \\ moreiratiago22@gmail.com (T.C.); bruno.manzolli@gmail.com (B.R.); rspessoa@ita.br (R.P.); \\ homero@ita.br (H.M.) \\ 2 Space Research and Technology Institute, Acad. G. Bonchev Str. Bl.1, 1113 Sofia, Bulgaria; kgrigoro@abv.bg \\ 3 Instituto de Ciência e Tecnologia, Universidade Federal de São Paulo, São José dos Campos 12231-280, \\ SP, Brazil \\ 4 Instituto Científico e Tecnológico, Universidade Brasil, Rua Carolina Fonseca 235, São Paulo 08230-030, Brazil \\ 5 Institut des Matériaux Jean Rouxel IMN, UMR 6502, Université de Nantes, 2 rue de La Houssinière, BP \\ 32229, 44322 Nantes CEDEX, France; jcamus@gmail.com (J.C.); abdou.djouadi@cnrs-imn.fr (M.D.) \\ * Correspondence: nierlly@gmail.com (N.G.); mafraga@ieee.org (M.F.)
}

Received: 10 February 2019; Accepted: 15 March 2019; Published: 22 March 2019

\begin{abstract}
Many strategies have been developed for the synthesis of silicon carbide ( $\mathrm{SiC}$ ) thin films on silicon ( $\mathrm{Si}$ ) substrates by plasma-based deposition techniques, especially plasma enhanced chemical vapor deposition (PECVD) and magnetron sputtering, due to the importance of these materials for microelectronics and related fields. A drawback is the large lattice mismatch between $\mathrm{SiC}$ and Si. The insertion of an aluminum nitride (AIN) intermediate layer between them has been shown useful to overcome this problem. Herein, the high-power impulse magnetron sputtering (HiPIMS) technique was used to grow $\mathrm{SiC}$ thin films on AlN/Si substrates. Furthermore, SiC films were also grown on $\mathrm{Si}$ substrates. A comparison of the structural and chemical properties of $\mathrm{SiC}$ thin films grown on the two types of substrate allowed us to evaluate the influence of the AlN layer on such properties. The chemical composition and stoichiometry of the samples were investigated by Rutherford backscattering spectrometry (RBS) and Raman spectroscopy, while the crystallinity was characterized by grazing incidence X-ray diffraction (GIXRD). Our set of results evidenced the versatility of the HiPIMS technique to produce polycrystalline $\mathrm{SiC}$ thin films at near-room temperature by only varying the discharge power. In addition, this study opens up a feasible route for the deposition of crystalline $\mathrm{SiC}$ films with good structural quality using an AlN intermediate layer.

Keywords: high-power impulse magnetron sputtering (HiPIMS); silicon carbide; aluminum nitride; thin film; Rutherford backscattering spectrometry (RBS); grazing incidence X-ray diffraction (GIXRD); Raman spectroscopy
\end{abstract}

\section{Introduction}

Silicon carbide $(\mathrm{SiC})$ has been proven to be a promising material for microelectronic applications due to its excellent physical and electronic properties, such as high surface hardness, wide bandgap, and high thermal conductivity at low and high temperatures [1-6]. These outstanding properties 
make it an attractive material for the development of harsh-environment devices such as Micro-Electro-Mechanical Systems (MEMS) and power electronics [1,2,7-9]. In a recent article, Dinh et al. showed an on-chip SiC MEMS device for efficient thermal management [10]. Furthermore, the strain effect in a highly doped 3C-SiC-on-glass substrate for mechanical sensors was also recently reported by Phan et al. [11]. The 3C-SiC bridges were also investigated under the consideration of Joule heating [12].

For microelectronic device applications, it is desirable for $\mathrm{SiC}$ thin films to be grown on $\mathrm{Si}$ substrates because their manufacturing processes are based on $\mathrm{Si}$ microfabrication technology, which is compatible with standard industrial processes [8,13-15]. It is difficult to grow high-quality crystalline $\mathrm{SiC}$ (c-SiC) films on Si substrates at low temperatures $\left(<300^{\circ} \mathrm{C}\right)$ due to a large mismatch between their lattice constant (about 20\%) and thermal expansion coefficients (about $8 \%$ ), which usually affects the final properties of the grown material [16]. In order to reduce these effects, an intermediate or buffer layer may be added. For this purpose, aluminum nitride (AlN) thin film is frequently used since it presents minimum mismatching in the lattice constant (less $1 \%$ ) with $\mathrm{SiC}$, and has a similar thermal expansion coefficient [17-20].

Meguro et al. investigated the formation of a SiC interfacial buffer layer on AlN/Si substrates at a low temperature by low-pressure chemical vapor deposition (LPCVD) [17]. Nakazawa et al. reported the epitaxial growth of SiC films on an AlN layer on $\mathrm{Si}(100)$ substrates by ultralow-pressure chemical vapor deposition. Jeong et al. investigated the Raman scattering characteristics of 3C-SiC films deposited on AlN/Si substrates using the atmosphere pressure chemical vapor deposition (APCVD) technique [19]. Huang et al. demonstrated the formation of $\mathrm{SiC}$ quantum dots (SiC QDs) on AlN films using low-frequency inductively coupled plasma (LF-ICP)-assisted magnetron sputtering [20]. To our knowledge, the study here presented is the first to report the growth of high-power impulse magnetron sputtering (HiPIMS) of $\mathrm{SiC}$ films on AlN/Si substrates.

The achievement of good crystallinity in the $\mathrm{SiC}$ thin films is a desirable feature since it influences different material properties [21]. As the $\mathrm{SiC}$ thin films deposited at low temperature grow in amorphous or nanocrystalline structures, post-treatment such as annealing, to improve the material crystallinity, is necessary. Although there are several well-known techniques for synthesizing SiC thin films, their composition and final properties may vary considerably with the applied method $[3,19]$. Low-pressure plasma-based techniques have been extensively investigated, particularly those that allow the deposition at near-room temperatures, such as plasma-enhanced chemical vapor deposition (PECVD) and magnetron sputtering [1,3,22-25]. Along with the magnetron sputtering derivations, the high-power impulse magnetron sputtering (HiPIMS) technique appears to be very attractive due to its ability to generate high-density plasmas and a high degree of ionization of the sputtered atoms [26-31]. These properties allow sufficient energy for the rearrangement of atoms/molecules during the growth of the film, thus facilitating the formation of crystalline phases. Some reports have demonstrated that, depending on the deposition parameters and target composition, around $50-90 \%$ of the sputtering atoms are in an ionized state $[24,28,30]$. This occurs because of the mechanism in which the HiPIMS power supply applies the power over the magnetron target for generating the plasma, namely high-power pulses, low frequency, and low duty cycles (lower than 10\%) [28,30-32]. Interesting reviews on HiPIMS were written by Sarakinos et al. [30] and Gudmundsson et al. [31].

Although the HiPIMS source is applied in the synthesis of various metals and semiconductor materials, there is a clear lack of studies focusing on the growth of $\mathrm{SiC}$ thin films using this technique. The studies related to this topic are focused on Ti-Si-C and SiCN films using HiPIMS [26,33]. In the work of Alami et al. [33], the effect of processing parameters such as gas pressure, substrate geometry, and distance of the target substrate on some properties of the as-deposited Ti-Si-C film was investigated. They observed that the Ti-Si-C film quality could be improved by the HiPIMS technique [33]. Pusch et al. performed a comparison between SiCN films deposited with different target configurations and techniques, i.e., radiofrequency (RF), direct current (DC), and HiPIMS [26]. Leal et al. deposited SiC thin films on Si substrates by HiPIMS using a SiC target [34]; however, 
only amorphous films were obtained. In this article, we explore the structural and chemical properties of polycrystalline $\mathrm{SiC}$ films grown at room temperature on $\mathrm{Si}$ and AlN/Si substrates by the HiPIMS technique. The composition, chemical bonding, structure, and crystallinity of the samples were investigated by Rutherford backscattering spectrometry (RBS), Raman spectroscopy, and grazing incidence X-ray diffraction (GIXRD).

\section{Materials and Methods}

\subsection{Deposition Method}

$\mathrm{SiC}$ thin films were grown onto polished p-type Si (100) wafers, either with or without an AlN layer, via HiPIMS in a high-vacuum chamber with a background pressure of $6 \times 10^{-6}$ Torr. More details about the HiPIMS reactor can be found elsewhere [34,35]. The working pressure of the argon gas (99.999\%, White-Martins, São José dos Campos, Brazil) was maintained at 3 mTorr for a corresponding flow rate of $20 \mathrm{sccm}$ (standard centimeter cubic per minute). The target was a commercial high-purity SiC (99.5\%, Kurt J. Lesker Company, Jefferson Hills, PA, USA) with a diameter of 4 inches. For film growth, the applied power from the HiPIMS power supply (HIP $5 \mathrm{~kW}$, Solvix SA, Villaz-Saint-Pierre, Switzerland) was $200 \mathrm{~W}$ and $400 \mathrm{~W}$. In all cases, the duty cycle was fixed at $5 \%$, frequency at $500 \mathrm{~Hz}$, and pulse time at $100 \mu$ s. To remove the target surface contaminants, a pre-sputtering time of $200 \mathrm{~W}$ for $10 \mathrm{~min}$ was applied. In addition, the substrate holder was maintained at a floating potential, whereas the deposition time and the target-substrate distance were fixed at $60 \mathrm{~min}$ and $60 \mathrm{~mm}$, respectively.

The AlN/Si substrates were provided by the "Institut des Matériaux Jean Rouxel in Nantes University". In these substrates, the sputtered AlN intermediate layer had a thickness of $1300 \mathrm{~nm}$ and a (002) crystallographic orientation. For more details, see References [36,37].

\subsection{Characterization Techniques}

Rutherford backscattering spectrometry (RBS) was used to measure the elemental composition, stoichiometry, and the thickness of the as-deposited $\mathrm{SiC}$ thin films. The measurements were performed with a pelletron accelerator using $2 \mathrm{MeV} 4 \mathrm{He}^{+}$beam with a particle detector positioned at $170^{\circ}$ from the incident beam. The RBS spectra were analyzed using the computer code RUMP (RBS analysis package) developed by L. R. Doolittle from Cornell University [38]. To verify the accuracy of the RBS thickness measurements and the thickness uniformity, mechanical profilometry (P-7 Stylus Profiler, KLA Tencor, Milpitas, CA, USA) measurements were performed.

The crystallinity of the $\mathrm{SiC}$ films was inferred from GIXRD with incidence angles $(\omega)$ of $1.0^{\circ}, 1.5^{\circ}$, and $2.0^{\circ}$ using an X-ray diffractometer (PW1830/1840, Philips, Amsterdam, The Netherlands) with $\mathrm{CuK}_{\alpha}$ radiation. For Raman spectroscopy measurements, a model 2000 Renishaw system (Renishaw, Wotton-under-Edge, UK), equipped with an Ar ion laser (514.5 nm) was used. Raman spectra were obtained at room temperature in the range of $400-1800 \mathrm{~cm}^{-1}$.

\section{Results and Discussion}

\subsection{Chemical Composition and Stoichiometry}

Figure 1 shows the experimental and simulated RBS spectra of the as-deposited SiC thin films on $\mathrm{Si}$ and AlN/Si substrates for the $200 \mathrm{~W}$ and $400 \mathrm{~W}$ conditions. Table 1 summarizes the results of the RBS spectra analysis.

Figure 1a depicts the spectrum of $\mathrm{SiC}$ deposited on $\mathrm{Si}$ at $200 \mathrm{~W}$ and the simulation reveals a film with a total thickness of approximately $1200 \mathrm{~nm}$, with a highly non-homogenous elemental distribution throughout the film depth. To better visualize the variation of the stoichiometry throughout the film depth, the simulation comprised five sublayers which are identified in Table 1. The top layer's stoichiometry comprised $260 \mathrm{~nm}$ of pure $\mathrm{SiC}$ with less than $13 \%$ oxygen. The middle part 
(approximately $400 \mathrm{~nm}$ ) consisted of $\mathrm{SiC}$ with 10\% excess carbon. The next layer with a thickness of $250 \mathrm{~nm}$ had about $50 \%$ carbon excess and a substantial drop in the oxygen content was observed. The subsequent layer of $170 \mathrm{~nm}$ was fully stoichiometric, followed by the last layer of $145 \mathrm{~nm}$ adjacent to the Si surface, where $10 \%$ carbon excess was found. When investigating the incorporated oxygen in the first layers of the $\mathrm{SiC}$ film, Medeiros et al. observed the unintentional doping of $\mathrm{SiC}_{\mathrm{x}} \mathrm{N}_{\mathrm{y}}$ thin films by oxygen contamination coming from the vacuum environment of the magnetron co-sputtering system [35]. In this work, RBS results showed that all samples contained significant amounts of oxygen (up to 16\%). Further, X-ray photoelectron spectroscopy (XPS) results showed that most of this oxygen is located in the film surface [35]. These results corroborate with the RBS analysis presented in Figure 1a. In addition, Pomaska et al. presented studies on the unintentional doping by oxygen contamination where they demonstrated that the oxygen incorporation was influenced the microstructural, electronic, and optical properties of the $\mathrm{SiC}$ films [39]. It has been shown that oxygen incorporation during film deposition increases the crystallinity of $\mathrm{SiC}$ films, consistent with findings observed in this work.
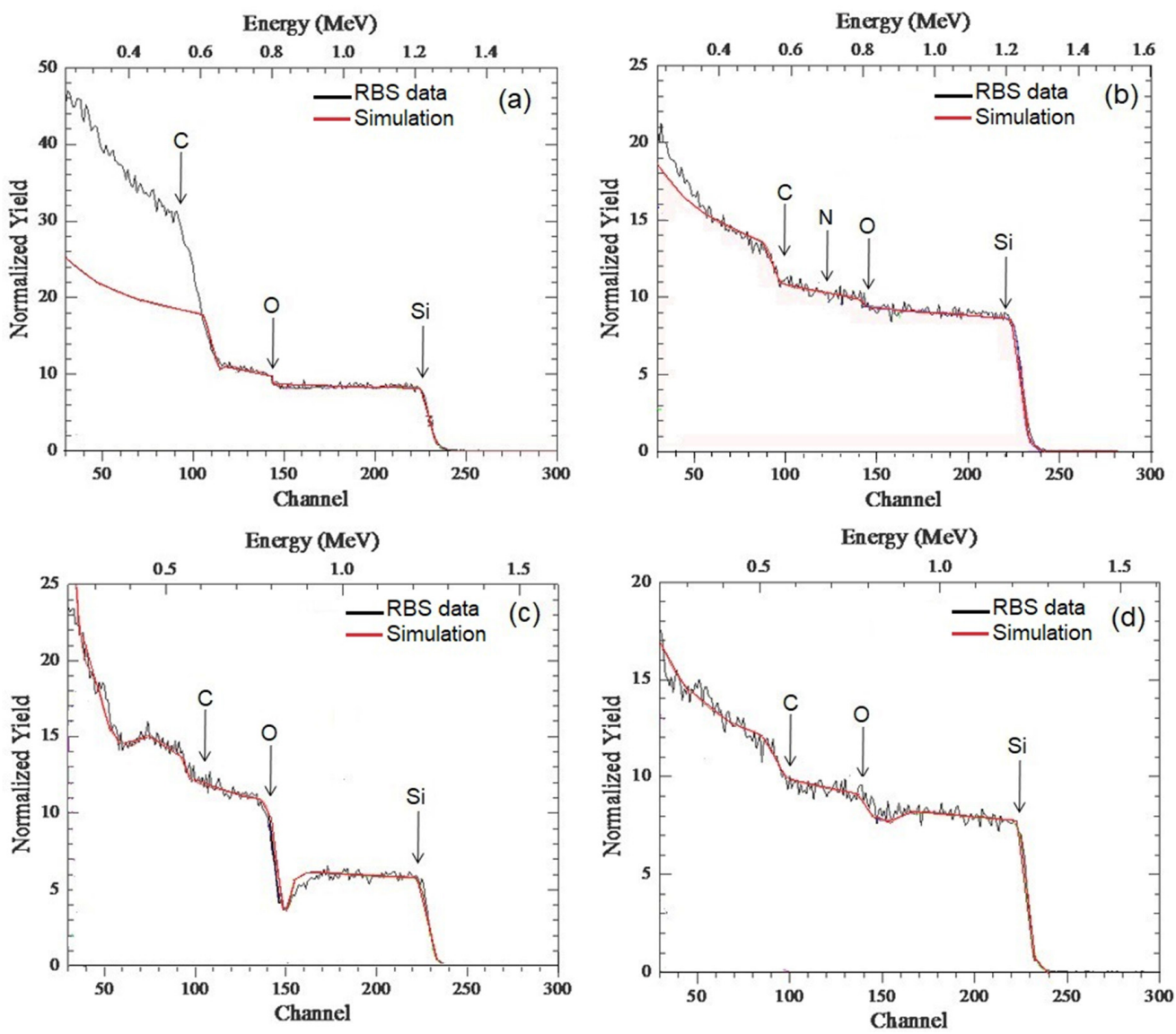

Figure 1. Experimental and simulated Rutherford backscattering spectrometry (RBS) spectra of the SiC films deposited on (a) Si substrate at $200 \mathrm{~W}$; (b) Si substrate at $400 \mathrm{~W}$; (c) AlN/Si substrate at $200 \mathrm{~W}$ and; (d) AlN/Si substrate at $400 \mathrm{~W}$.

For the SiC grown on the Si substrate at $400 \mathrm{~W}$ (Figure 1b), the analysis of the RBS spectra indicated that the total film thickness was around $1500 \mathrm{~nm}$. The film exhibited a pure and stoichiometric composition of $\mathrm{SiC}$ throughout the entire depth, although two zones could be distinguished as presented in Table 1 . Beyond the $\mathrm{SiC}, \mathrm{SiO}_{2}$, and $\mathrm{SiN}$ phases, there were $\mathrm{O}$ and $\mathrm{N}$ contaminants. This sputtering condition resulted in a heterogeneous film composition with variable elemental depth distributions. In general, the higher power deposition energy, as in this case, leads to Ar ions striking onto the film surface with high energy, which contributes to the formation of chemical phases. 
Of course, if different impurities act as film constituents, they are involved in the film composition forming stable bonds $\left(\mathrm{SiO}_{2} ; \mathrm{SiN}\right)$.

From the thickness results of the SiC films grown at $200 \mathrm{~W}(1200 \mathrm{~nm})$ and $400 \mathrm{~W}(1500 \mathrm{~nm})$, it is possible to observe that although the applied power is twice as high, there was a small increase in the deposition rate for $\mathrm{SiC}$ films on the $\mathrm{Si}$ substrate. In conventional sputtering processes, the deposition rate of the $\mathrm{SiC}$ film increases linearly with the sputtering power $[23,24]$. In general, HiPIMS exhibits different growth mechanisms and lower deposition rates than those observed for conventional sputtering processes [30,31,40]. Different effects have been considered to explain the differences between DC and HiPIMS deposition rates. There are three main reasons considered [41]: (i) the less-than-linear increase of the sputtering yield with increasing ion energy, ion return to the target, and self-sputtering; (ii) ion return to the target and self-sputtering; and (iii) changes due to greater film density, limited sticking, and self-sputtering on the substrate.

Table 1. Results of the RBS analysis.

\begin{tabular}{|c|c|c|c|}
\hline Sample & No. of Layers & Composition by Layer $^{1}$ & Layer Thickness \\
\hline $\begin{array}{l}\mathrm{SiC} / \mathrm{Si} \\
200 \mathrm{~W}\end{array}$ & 5 & $\begin{array}{l}\text { 1. } \mathrm{SiC} \text { stoichiometry with less than } 13 \% \text { oxygen. } \\
\text { 2. } \mathrm{SiC} \text { with about } 10 \% \text { excess carbon. } \\
\text { 3. } \mathrm{SiC} \text { with about } 50 \% \text { excess carbon. } \\
\text { 4. } \mathrm{SiC} \text { stoichiometry. } \\
\text { 5. } \mathrm{SiC} \text { with about } 10 \% \text { excess carbon. }\end{array}$ & $\begin{array}{l}\text { 1. } 260 \mathrm{~nm} \\
\text { 2. } 400 \mathrm{~nm} \\
\text { 3. } 250 \mathrm{~nm} \\
\text { 4. } 170 \mathrm{~nm} \\
\text { 5. } 145 \mathrm{~nm}\end{array}$ \\
\hline $\begin{array}{l}\mathrm{SiC} / \mathrm{Si} \\
400 \mathrm{~W}\end{array}$ & 2 & $\begin{array}{l}\text { 1. } \mathrm{SiC}-86 \% ; \mathrm{SiO}_{2} \text { phase- } 4 \% \text { dispersed in that } \\
\text { volume; } \mathrm{O}-5 \% ; \mathrm{N}-5 \% \text {. } \\
\text { 2. } \mathrm{SiC}-50 \% \text { and } \mathrm{SiN}-50 \% \text {. }\end{array}$ & $\begin{array}{l}\text { 1. } \sim 900 \mathrm{~nm} \\
\text { 2. } \sim 600 \mathrm{~nm}\end{array}$ \\
\hline $\begin{array}{l}\mathrm{SiC} / \mathrm{AlN} / \mathrm{Si} \\
200 \mathrm{~W}\end{array}$ & 2 & $\begin{array}{l}\text { 1. SiC stoichiometry- } 56 \% \text {; C solid state and O } \\
\text { contamination in } 44 \% \text {. } \\
\text { 2. AlN layer stoichiometry. }\end{array}$ & $\begin{array}{l}\text { 1. } \sim 930 \mathrm{~nm} \\
\text { 2. } \sim 1300 \mathrm{~nm}\end{array}$ \\
\hline $\begin{array}{c}\mathrm{SiC} / \mathrm{AlN} / \mathrm{Si} \\
400 \mathrm{~W}\end{array}$ & 2 & $\begin{array}{l}\text { 1. } \mathrm{SiC} \text { stoichiometry- } 80 \% \text { with } 20 \% \mathrm{C} \text { solid state } \\
\text { and } \mathrm{O} \text { contamination in volume. } \\
\text { 2. AlN layer stoichiometry. }\end{array}$ & $\begin{array}{l}\text { 1. } \sim 1360 \mathrm{~nm} \\
\text { 2. } \sim 1300 \mathrm{~nm}\end{array}$ \\
\hline
\end{tabular}

For the SiC film deposited on AlN/Si at $200 \mathrm{~W}$, the total film thickness was around $930 \mathrm{~nm}$ (Figure 1c). The film composition was rather homogenous and consisted of $56 \%$ pure $\mathrm{SiC}$, while the remaining $44 \%$ of the film was composed of $\mathrm{C}$ and $\mathrm{O}$ in the bulk of the film. The intermediate layer of AlN consisted of $1300 \mathrm{~nm}$ thick sub-stoichiometric AlN with 5\% less nitrogen, resulting in some point defects. Note that in this case the substrate change provided the growth of a high stoichiometric $\mathrm{SiC}$ film. Relative to film thickness, it is evidenced from data presented in Table 1 that the change of $\mathrm{Si}$ with AlN/Si substrate promoted the decrease in the thickness of the SiC film. Although sputtering processes have deposition rates that are independent of the substrate type, the film nucleation process and consequent crystallization and compaction are dependent. Nivedita et al. confirmed some of these observations when depositing RF-sputtered Fe-Ga thin films on $\mathrm{MgO}$, quartz, and Si substrates [42]. Indeed, the next topic shows that the crystallization of $\mathrm{SiC}$ is improved for films deposited on $\mathrm{Si}$. Crystalline films tend to have greater roughness and even porosity in comparison with amorphous films, which consequently increases the final thickness [43].

The SiC thin film deposited on AlN/Si at $400 \mathrm{~W}$ (Figure 1d) exhibited a high percentage of purely stoichiometric $\mathrm{SiC}$ film, with the presence of $\mathrm{C}$ and $\mathrm{O}$ in volume. However, for this condition the estimate of the thickness by RBS was limited due to the loss of the energy via scattering albeit within certain limits, e.g., above channel $n^{\circ} 90$ (Figure 1d), the thickness could be estimated as being around $1360 \mathrm{~nm}$. Ultimately, the elemental depth distribution throughout the film thickness was 
uniform, which made the present method and processing conditions very useful for the achievement of high-quality $\mathrm{SiC}$ thin film deposition.

Finally, from the results in Table 2, it was possible to observe that the calculated deposition rates of the $\mathrm{SiC}$ films were in agreement with the profilometry measurements. With regard to the deposition rates measured by profilometry, and where the film thicknesses were measured at different points during the formation of the film, it was possible to evaluate the uniformity of the film thickness, which exhibited a 3\% variation throughout the substrate. In fact, the greater the target-substrate distance in processes performed by magnetron sputtering, the better the uniformity of the film formed, where a distance of $60 \mathrm{~mm}$ was used. With regard to the film morphology, in previous work [44] Atomic force microscopy (AFM) analyses of the SiC/AlN/Si film and the AlN/Si film were performed, showing films with rough surfaces and with grain sizes smaller than $100 \mathrm{~nm}$.

Table 2. Deposition rate of the SiC films.

\begin{tabular}{cccc}
\hline Sample & Power $(\mathbf{W})$ & Deposition Rate-RBS (nm/min) & Deposition Rate-Profilometer (nm/min) \\
\hline $\mathrm{SiC} / \mathrm{Si}$ & 200 & 20.0 & $14.0 \pm 0.3$ \\
$\mathrm{SiC} / \mathrm{Si}$ & 400 & 25.0 & $19.6 \pm 0.4$ \\
$\mathrm{SiC} / \mathrm{AlN} / \mathrm{Si}$ & 200 & 15.5 & $12.5 \pm 0.4$ \\
$\mathrm{SiC} / \mathrm{AlN} / \mathrm{Si}$ & 400 & 22.7 & $24.0 \pm 0.5$ \\
\hline
\end{tabular}

\subsection{Structural Analysis}

Figures $2-4$ show the patterns of grazing incidence angles of $1.0^{\circ}, 1.5^{\circ}$, and $2.0^{\circ}$, respectively. The Bragg reflections suggest the existence of $\alpha$ and $\beta \mathrm{SiC}$ nanocrystalline structures. Although the patterns exhibit the $\mathrm{SiC}$ phase, it is not possible to determine which of the $\mathrm{SiC}$ phases are present because some diffraction peaks of $\alpha$ and $\beta \mathrm{SiC}$ might overlap [45]. The carbon phase at $\sim 25^{\circ}$ was also visible and confirmed the RBS results indicating an excess of C (Table 1). Lastly, two broad peaks at $\sim 47^{\circ}$ and $55^{\circ}$ were assigned as unidentified. While some studies have attributed these peaks to the $\mathrm{SiC}$ polymorph phase [46,47], others often define them as being $\mathrm{C}$ or Si phases [48-50]. When comparing the results from the GIXRD with an incidence angle of $2^{\circ}$ (Figure 4 ) with the smaller angle results, the variation of the crystalline phases with the depth of the film was clearly noted.

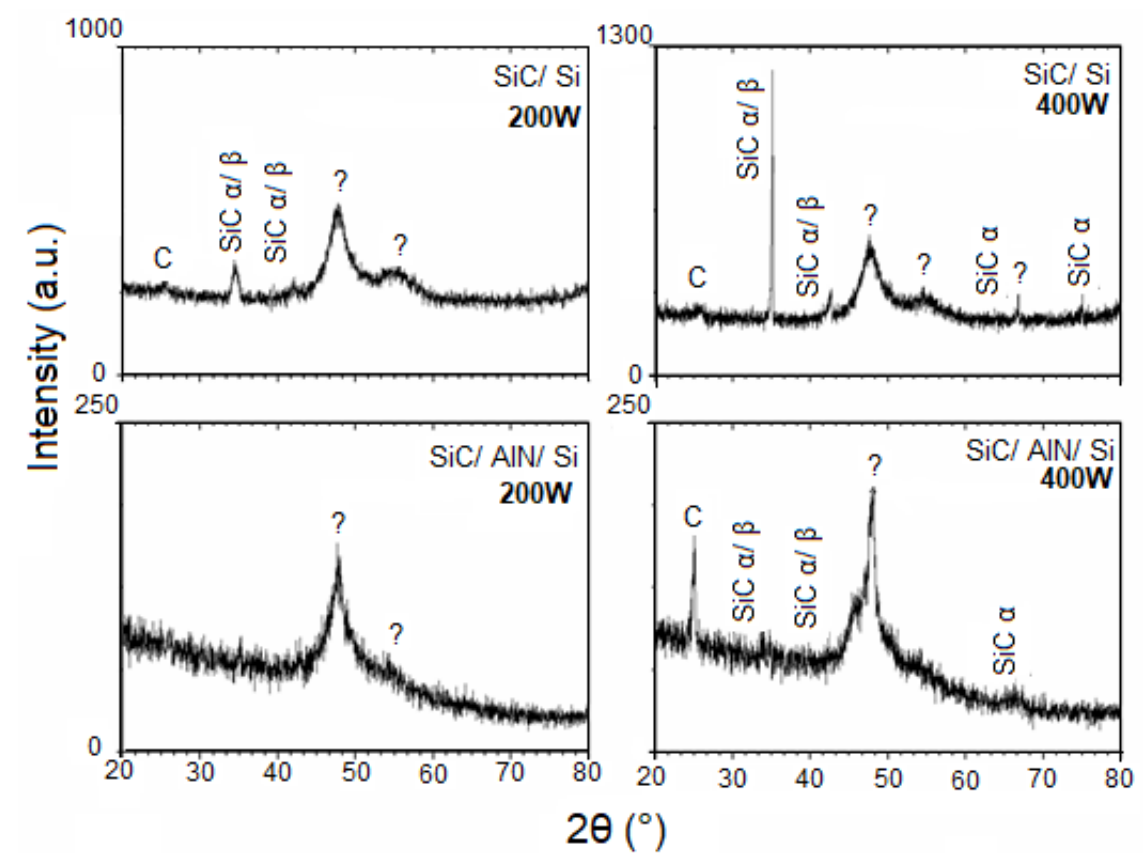

Figure 2. Grazing incidence X-ray diffraction (GIXRD) patterns of the SiC thin films at a grazing angle of $1.0^{\circ}$. 
In addition, Figure 2 suggests the existence of $\mathrm{SiC}$ nanocrystalline structures achieved without substrate heating. By varying the GIXRD incidence angle, the resulting film could be analyzed in depth. A comparison of the patterns between SiC/Si and SiC/AlN/Si for both angles of incidence $\left(1^{\circ}\right.$ and $\left.1.5^{\circ}\right)$, revealed that the phase observed at approximately $36^{\circ}$, using the $1.5^{\circ}$ GIXRD as the incidence angle, no longer existed in the pattern obtained with the smallest angle $\left(1.0^{\circ}\right)$. This result pointed to the existence of phase and crystallinity variations with depth.

The film deposited on the AlN layer showed dislocation of the SiC peak between 35 and $36^{\circ}$ in the GIXRD patterns. This dislocation may be attributed to the following reasons: (i) film stress; (ii) interference of the substrate ( $\mathrm{SiC} / \mathrm{Si}$ and $\mathrm{SiC} / \mathrm{AlN}$ interface); or (iii) residual stress. More studies are necessary to better understand this observation.

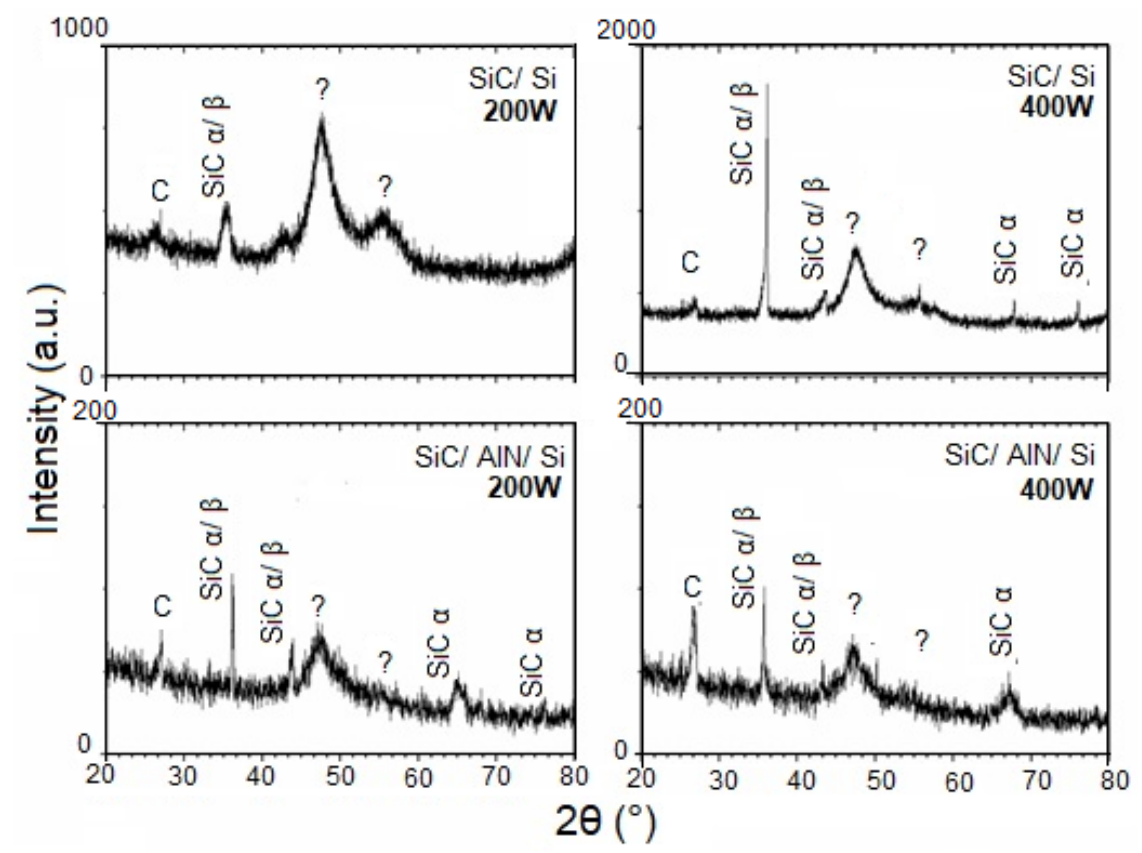

Figure 3. GIXRD patterns of the $\mathrm{SiC}$ thin films at a grazing angle of $1.5^{\circ}$.
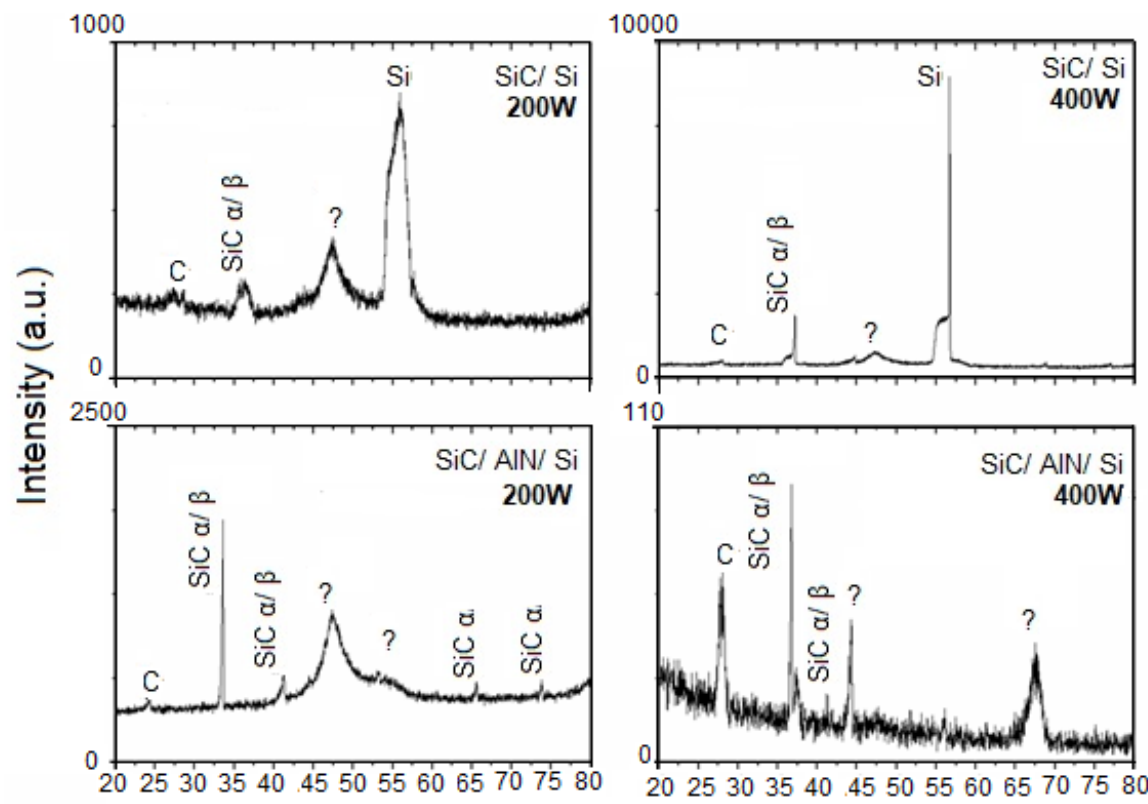

$2 \theta\left({ }^{\circ}\right)$

Figure 4. GIXRD patterns of the $\mathrm{SiC}$ thin films at a grazing angle of $2^{\circ}$. 


\subsection{Raman Spectroscopy}

Figure 5 shows the results of Raman spectroscopy used to identify the bonds present in the films. The Raman spectra for the SiC films deposited at $200 \mathrm{~W}$ in both substrates (with and without the AlN layer) are presented in Figure 5a, showing a very visible and well-defined Si peak at $519.41 \mathrm{~cm}^{-1}$. Since the difference in thickness between both films was small, the substrate had an accentuated influence. In addition to $\mathrm{Si}$, the SiC film deposited on the AlN layer showed (i) a peak relative to AlN at $\sim 652.20 \mathrm{~cm}^{-1}$; (ii) peaks for $\mathrm{SiC}$ and $\mathrm{Si}$ in the regions between 741-894 $\mathrm{cm}^{-1}$ and $906-1109 \mathrm{~cm}^{-1}$, respectively; (iii) and a broad carbon band at 1370-1625 $\mathrm{cm}^{-1}$. Except for the AlN peak, the SiC/Si spectrum exhibited signals at similar regions to that of the $\mathrm{SiC} / \mathrm{AlN} / \mathrm{Si}$ spectrum. However, the regions relative to $\mathrm{SiC}$ and $\mathrm{Si}$ were more visible, and the $\mathrm{C}$ band region had a more explicit separation in two peaks (D and G bands), but with a low definition of the disorder band. The D band was attributed to the disorder or polycrystalline carbon and the $\mathrm{G}$ band to the graphite-like carbon [19,50].
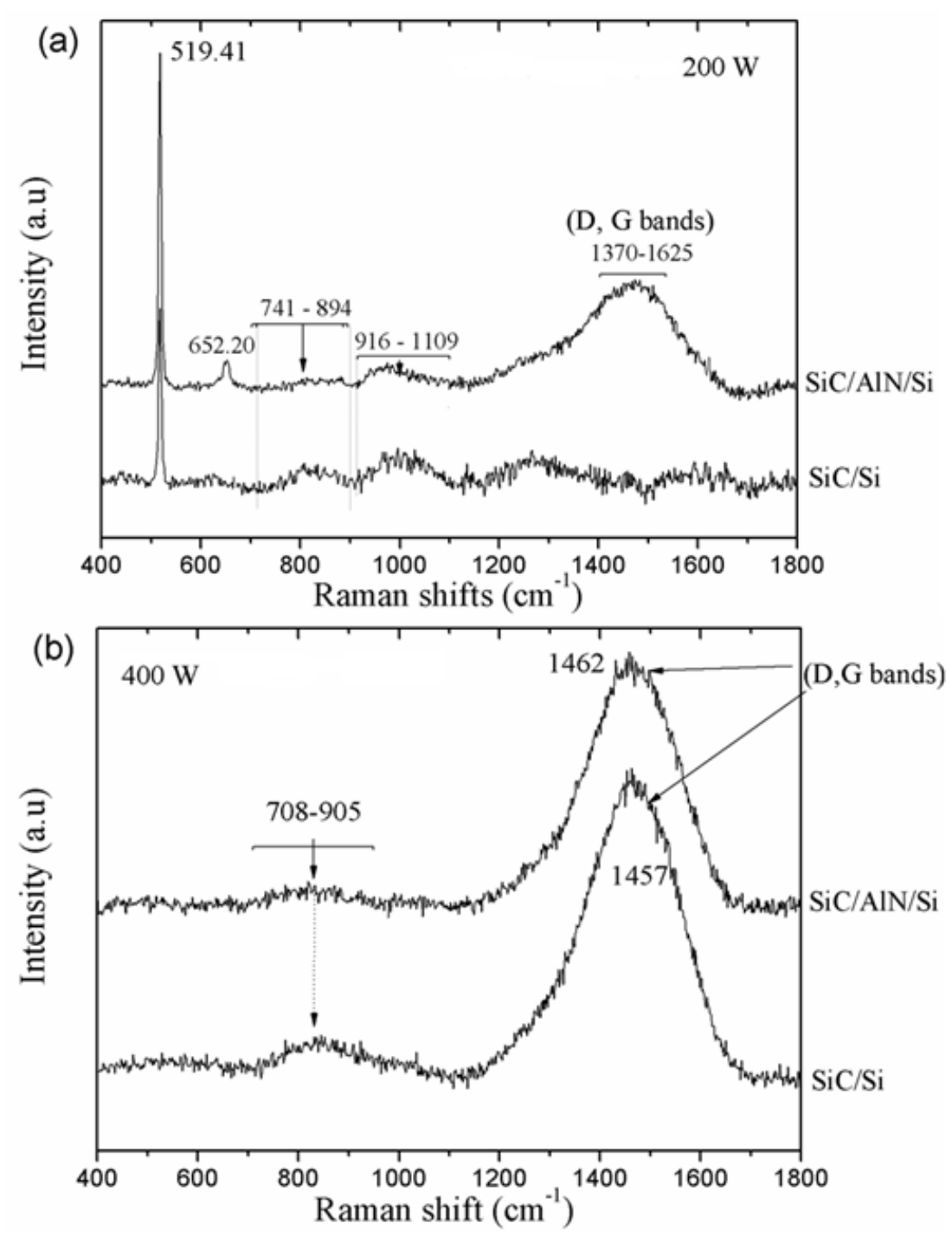

Figure 5. Raman spectra of $\mathrm{SiC}$ thin films on both substrates: (a) as-deposited at $200 \mathrm{~W}$ and (b) as-deposited at $400 \mathrm{~W}$.

For $400 \mathrm{~W}$ (Figure 5b), both substrates exhibited similar behavior following the deposition of SiC films. In these spectra, the substrate signal was not detected and only peaks corresponding to carbon at 1457 and $1462 \mathrm{~cm}^{-1}$ were evident. With the exception of the spectrum of the $\mathrm{SiC}$ film at $200 \mathrm{~W}$ of $\mathrm{SiC} / \mathrm{Si}$, where the peak of the $\mathrm{C}$ band was not overlapped, all spectra of the "as-deposited" SiC film showed 
overlapping C, D, and G bands between 1457 and $1462 \mathrm{~cm}^{-1}$. Ferrari and Robertson [51] reported that for $\mathrm{C}-\mathrm{C}$ bands, the Raman spectrum was influenced by factors such as disorder, clustering of the $\mathrm{sp}^{2}$ phase, the presence of $\mathrm{sp}^{2} \mathrm{C}$-rings or C-chains, and the ratio of $\mathrm{sp}^{2}$ to $\mathrm{sp}^{3}(\mathrm{I}(\mathrm{D}) / \mathrm{I}(\mathrm{G}))$. Thus, with an increasing disorder of the $C$ phase, the $G$ peak position can be moved, and the $D$ and $G$ peaks will therefore overlap $[19,50,51]$.

\section{Conclusions}

The influence of an AlN intermediate layer on the structural and chemical properties of HiPIMS SiC films grown on Si substrates was investigated using RBS, Raman spectroscopy, and GIXRD. The effect of the applied power $(200 \mathrm{~W}$ and $400 \mathrm{~W})$ was also considered. It was observed that the HiPIMS of SiC films can exhibit a complex growth mechanism and, depending on the process parameters, leads to the formation of films with an inhomogeneous composition throughout the depth of the Si substrate and a homogeneous composition for the AlN/Si substrate. This was verified by GIXRD using three different incidence angles $\left(1.0^{\circ}, 1.5^{\circ}\right.$, and $\left.2.0^{\circ}\right)$ which, besides confirming the RBS results, also evidenced the variation of crystallinity with the depth of the film. Raman spectroscopy analysis indicated the presence of $\mathrm{Si}-\mathrm{C}$ bonds and that the $\mathrm{C}-\mathrm{C}$ bond region was separated into two peaks (D and $G$ bands), but with a low definition of the disorder band. In summary, the results demonstrated that the HiPIMS technique and the use of an AlN intermediate layer allowed for the deposition of crystalline SiC films of good quality, without the need for substrate heating, with approximately $1.5 \mu \mathrm{m}($ at $400 \mathrm{~W}$ ) in only $60 \mathrm{~min}$, i.e., at a deposition rate of $25 \mathrm{~nm} / \mathrm{min}$. The good chemical and physical properties of the HiPIMS SiC films deposited on AlN/Si substrates highlights their potential benefits in nanotechnological applications. Indeed, we recently proposed the thermal decomposition of $\mathrm{SiC}$ thin films using a $\mathrm{CO}_{2}$ laser beam without a vacuum chamber for graphene synthesis. The use of an AlN layer proved to be important because it reduces the thermal stress between $\mathrm{SiC}$ and Si materials [44]. Other applications will be the subject of further work.

Author Contributions: N.G., M.G., T.C., K.G., R.P., and J.C. conducted the investigation and methodology, N.G., K.G., M.F., B.R., R.P., M.D., and H.M. participated in the writing of the original draft.

Funding: The following funding sources including the Brazilian agency program FAPESP/MCT/CNPq-PRONEX (grant No. 11/50773-0), MCTI/CNPq/Universal (grants No. 459688/2014-6, 437921/2018-2, and 421317/2018-3), FAPESP (grant No. 18/01265-1 and 14/18139-8), CAPES/ITA (process No. 23038.005802/2014-98), CAPES/PVE (process No. 88881.064970/2014-01 and BEX9796/12-6), PNPD-CAPES, and CNPq (grants No. 305496/2012-3 and 446545/2014-7) are gratefully acknowledged for their support.

Acknowledgments: We would like to thank LAS-INPE for the Raman spectroscopy and GIXRD measurements, and LAMFI-USP for the RBS measurements. The authors also thank Dr Julio César Sagas from UDESC-Santa Catarina/Brazil for discussions and operation of the HiPIMS reactor.

Conflicts of Interest: The authors declare no conflict of interest.

\section{References}

1. Fraga, M.A.; Bosi, M.; Negri, M. Silicon Carbide in Microsystem Technology—Thin Film Versus Bulk Material. In Advanced Silicon Carbide Devices and Processing, 1st ed.; Saddow, S., la Via, F., Eds.; InTech: Rijeka, Croatia, 2015; pp. 1-31.

2. Fraga, M.A.; Furlan, H.; Pessoa, R.S.; Massi, M. Wide bandgap semiconductor thin films for piezoelectric and piezoresistive MEMS sensors applied at high temperatures: An overview. Microsyst. Technol. 2014, 20, 9-21. [CrossRef]

3. Pessoa, R.S.; Fraga, M.A.; Santos, L.V.; Massi, M.; Maciel, H.S. Nanostructured thin films based on $\mathrm{TiO}_{2}$ and/or $\mathrm{SiC}$ for use in photoelectrochemical cells: A review of the material characteristics, synthesis and recent applications. Mater. Sci. Semicond. Process. 2015, 29, 56-68. [CrossRef]

4. Maboudian, R.; Carraro, C.; Senesky, D.G.; Roper, C.S. Advances in silicon carbide science and technology at the micro- and nanoscales. J. Vac. Sci. Technol. A 2013, 31, 050805. [CrossRef]

5. Müller, G.; Krötz, G.; Niemann, E. SiC for sensors and high-temperature electronics. Sens. Actuators A Phys. 1994, 43, 259-268. [CrossRef] 
6. Huang, J.; Wang, L.; Wen, J.; Wang, Y.; Lin, C.; Ostling, M. Effect of annealing on SiC thin films prepared by pulsed laser deposition. Diam. Relat. Mater. 1999, 8, 2099-2102. [CrossRef]

7. Ledermann, N.; Baborowski, J.; Muralt, P.; Xantopoulos, N.; Tellenbach, J. Sputtered silicon carbide thin films as protective coating for MEMS applications. Surf. Coat. Technol. 2000, 125, 246-250. [CrossRef]

8. Sarro, P.M. Silicon carbide as a new MEMS technology. Sens. Actuators A Phys. 2000, 82, 210-218. [CrossRef]

9. Fraga, M.A.; Pessoa, R.S.; Massi, M.; Maciel, H.S. Applications of SiC-Based Thin Films in Electronic and MEMS Devices. In Physics and Technology of Silicon Carbide Devices, 1st ed.; Hijikata, Y., Ed.; InTech: Rijeka, Croatia, 2012; pp. 313-336.

10. Dinh, T.; Phan, H.P.; Kashaninejad, N.; Nguyen, T.K.; Dao, D.V.; Nguyen, N.T. An On-Chip SiC MEMS Device with Integrated Heating, Sensing, and Microfluidic Cooling Systems. Adv. Mater. Interfaces 2018, 5, 1800764. [CrossRef]

11. Phan, H.P.; Nguyen, T.K.; Dinh, T.; Cheng, H.H.; Mu, F.; Lacopi, A.; Hold, L.; Dao, D.V.; Suga, T.; Senesky, D.G.; et al. Strain Effect in Highly-Doped n-Type 3C-SiC-on-Glass Substrate for Mechanical Sensors and Mobility Enhancement. Phys. Status Solidi A 2018, 215, 1870054. [CrossRef]

12. Balakrishnan, V.; Dinh, T.; Phan, H.P.; Kozeki, T.; Namazu, T.; Dao, D.V.; Nguyen, N.T. Steady-state analytical model of suspended p-type 3C-SiC bridges under consideration of Joule heating. J. Micromech. Microeng. 2017, 27, 075008. [CrossRef]

13. Roumié, M.; Tabbal, M.; Nsouli, B.; Said, A. Determination of stoichiometry in silicon carbide materials using elastic backscattering spectrometry. Nucl. Instrum. Methods Phys. Res. B 2007, 260, 637-641. [CrossRef]

14. Tabbal, M.; Said, A.; Hannoun, E.; Christidis, T. Amorphous to crystalline phase transition in pulsed laser deposited silicon carbide. Appl. Surf. Sci. 2007, 253, 7050-7059. [CrossRef]

15. Zhao, Y.M.; Sun, G.S.; Liu, X.S.; Li, J.Y.; Zhao, W.S.; Wang, L.; Li, J.M.; Zeng, Y.P. Heteroepitaxial Growth of 3C-SiC on Si (111) Substrate Using AlN as a Buffer Layer. Mater. Sci. Forum 2009, 600-603, 251-254. [CrossRef]

16. Severino, A. 3C-SiC epitaxial growth on large area silicon: Thin films. In Silicon Carbide Epitaxy, 1st ed.; la Via, F., Ed.; Research Singpost: Kerala, India, 2012; pp. 145-191.

17. Meguro, K.; Narita, T.; Noto, K.; Nakazawa, H. Formation of an interfacial buffer layer for 3C-SiC heteroepitaxy on AlN/Si substrates. Mater. Sci. Forum 2014, 778-780, 251-254. [CrossRef]

18. Nakazawa, H.; Suzuki, D.; Narita, T.; Meguro, K.; Tsuchiya, M. Growth of silicon carbide on Si (100) substrate with an intermediate aluminum nitride layer by ultralow-pressure chemical vapor deposition using monomethylsilane. J. Cryst. Growth 2015, 418, 52-56. [CrossRef]

19. Jeong, J.; Jang, K.; Lee, H.S.; Chung, G.; Kim, G. Raman scattering studies of polycrystalline 3C-SiC deposited on $\mathrm{SiO}_{2}$ and AlN thin films. Phys. B Condens. Matter 2009, 404, 7-10. [CrossRef]

20. Huang, S.Y.; Xu, S.; Long, J.D.; Sun, Z.; Chen, T. Plasma-reactive SiC quantum dots on polycrystalline AlN films. Phys. Plasmas 2006, 13, 023506. [CrossRef]

21. Fraga, M.A.; Pessoa, R.S.; Maciel, H.S.; Massi, M. Recent Developments on Silicon Carbide Thin Films for Piezoresistive Sensors Applications. In Silicon Carbide-Materials, Processing and Applications in Electronic Devices; Mukherjee, M., Ed.; InTech: Rijeka, Croatia, 2011; pp. 369-388.

22. Tang, H.; Tan, S.; Huang, Z.; Dong, S.; Jiang, D. Surface morphology of $\alpha$-SIC coatings deposited by RF magnetron sputtering. Surf. Coat. Technol. 2005, 197, 161-167. [CrossRef]

23. Gou, L.; Qi, C.; Ran, J.; Zheng, C. SiC film deposition by DC magnetron sputtering. Thin Solid Film. 1999, 345, 42-44. [CrossRef]

24. Medeiros, H.S.; Pessoa, R.S.; Maciel, H.S.; Massi, M.; Tezani, L.L.; Leal, G.; Galvão, N.K.A.M.; da Silva Sobrinho, A.S. Amorphous Silicon Carbide Thin Films Deposited by Magnetron Co-Sputtering: Effect of Applied Power and Deposition Pressure on Film Characteristics. ECS Trans. 2012, 49, 375-382. [CrossRef]

25. Lei, Y.M.; Yu, L.H.; Cheng, L.L.; Ren, C.X.; Zou, S.C.; Wong, S.P.; Chen, D.H.; Wilson, I.H. IR studies of reactive DC magnetron sputtered $\mathrm{SiC}$ films on silicon using effective medium theory. Mater. Lett. 2000, 43, 215-219. [CrossRef]

26. Pusch, C.; Hoche, H.; Berger, C.; Riedel, R.; Ionescu, E.; Klein, A. Influence of the PVD sputtering method on structural characteristics of SiCN-coatings-Comparison of RF, DC and HiPIMS sputtering and target configurations. Surf. Coat. Technol. 2011, 205, s119-s123. [CrossRef]

27. Bräuer, G.; Szyszka, B.; Vergo, M.; Bandorf, R. Magnetron sputtering-Milestones of 30 years. Vacuum 2010, 84, 1354-1359. [CrossRef] 
28. Anders, A. High power impulse magnetron sputtering and related discharges: Scalable plasma sources for plasma-based ion implantation and deposition. Surf. Coat. Technol. 2010, 204, 2864-2868. [CrossRef]

29. Aijaz, A.; Lundin, D.; Larsson, P.; Helmersson, U. Dual-magnetron open field sputtering system for sideways deposition of thin films. Surf. Coat. Technol. 2010, 204, 2165-2169. [CrossRef]

30. Sarakinos, K.; Alami, J.; Konstantinidis, S. High power pulsed magnetron sputtering: A review on scientific and engineering state of the art. Surf. Coat. Technol. 2010, 204, 1661-1684. [CrossRef]

31. Gudmundsson, J.T. The high power impulse magnetron sputtering discharge as an ionized physical vapor deposition tool. Vacuum 2010, 84, 1360-1364. [CrossRef]

32. Alami, J.; Bolz, S.; Sarakinos, K. High power pulsed magnetron sputtering: Fundamentals and applications. J. Alloys Compd. 2009, 483, 530-534. [CrossRef]

33. Alami, J.; Eklund, P.; Emmerlich, J.; Wilhelmsson, O.; Jansson, U.; Högberg, H.; Hultman, L.; Helmersson, U. High-power impulse magnetron sputtering of $\mathrm{Ti}-\mathrm{Si}-\mathrm{C}$ thin films from a $\mathrm{Ti}_{3} \mathrm{SiC}_{2}$ compound target. Thin Solid Film. 2006, 515, 1731-1736. [CrossRef]

34. Leal, G.; Campos, T.M.B.; da Silva Sobrinho, A.S.; Pessoa, R.S.; Maciel, H.S.; Massi, M. Characterization of $\mathrm{SiC}$ thin films deposited by HiPIMS. Mater. Res. 2014, 17, 472-476. [CrossRef]

35. Medeiros, H.S.; Pessoa, R.S.; Sagas, J.C.; Fraga, M.A.; Santos, L.V.; Maciel, H.S.; Massi, M.; da Silva Sobrinho, A.S.; Costa, M.E.H.M. Effect of nitrogen content in amorphous $\mathrm{SiC}_{\mathrm{x}} \mathrm{N}_{\mathrm{y}} \mathrm{O}_{z}$ thin films deposited by low temperature reactive magnetron co-sputtering technique. Surf. Coat. Technol. 2011, 206, 1787-1795. [CrossRef]

36. Belkerk, B.E.; Soussou, A.; Carette, M.; Djouadi, M.A.; Scudeller, Y. Structural-dependent thermal conductivity of aluminium nitride produced by reactive direct current magnetron sputtering. Appl. Phys. Lett. 2012, 101, 151908. [CrossRef]

37. Aissa, K.A.; Achour, A.; Camus, J.; Brizoual, L.L.; Jouan, P.; Djouadi, A. Comparison of the structural properties and residual stress of AlN films deposited by dc magnetron sputtering and high power impulse magnetron sputtering at different working pressures. Thin Solid Film. 2014, 550, 264-267. [CrossRef]

38. Doolittle, L.R. Algorithms for the rapid simulation of Rutherford backscattering spectra. Nucl. Instrum. Methods Phys. Res. Sect. B Beam Interact. Mater. At. 1985, 9, 344-351. [CrossRef]

39. Pomaska, M.; Mock, J.; Köhler, F.; Zastrow, U.; Perani, M.; Astakhov, O.; Cavalcoli, D.; Carius, R.; Finger, F.; Ding, K. Role of oxygen and nitrogen in n-type microcrystalline silicon carbide grown by hot wire chemical vapor deposition. J. Appl. Phys. 2016, 120, 225105. [CrossRef]

40. Diyatmika, W.; Liang, F.; Lou, B.; Lu, J.; Sun, D.; Lee, J. Superimposed high power impulse and middle frequency magnetron sputtering: Role of pulse duration and average power of middle frequency. Surf. Coat. Technol. 2018, 352, 680-689. [CrossRef]

41. Anders, A. Deposition Rates of High-Power Impulse Magnetron Sputtering: Physics and Economics J. Vac. Sci. Technol. A 2010, 28, 783. [CrossRef]

42. Nivedita, L.R.; Kumar, V.V.S.; Asokan, K.; Rajendrakumar, R.T. Growth and Magnetic Properties of RF Sputtered Fe-Ga Thin Films. Mater. Res. 2015, 18, 946-952. [CrossRef]

43. Jung, C.-K.; Lim, D.-C.; Jee, H.-G.; Park, M.-G.; Ku, S.-J.; Yu, K.-S.; Hong, B.; Lee, S.-B.; Boo, J.-H. Hydrogenated amorphous and crystalline $\mathrm{SiC}$ thin films grown by RF-PECVD and thermal MOCVD; comparative study of structural and optical properties. Surf. Coat. Technol. 2003, 171, 46-50. [CrossRef]

44. Galvão, N.; Vasconcelos, G.; Pessoa, R.; Machado, J.; Guerino, M.; Fraga, M.; Rodrigues, B.; Camus, J.; Djouadi, A.; Maciel, H. A Novel Method of Synthesizing Graphene for Electronic Device Applications. Materials 2018, 11, 1120. [CrossRef]

45. Li, W.; Yuan, J.; Lin, Y.; Yao, S.; Ren, Z.; Wang, H.; Wang, M.; Bai, J. The controlled formation of hybrid structures of multi-walled carbon nanotubes on $\mathrm{SiC}$ plate-like particles and their synergetic effect as a filler in poly(vinylidene fluoride) based composites. Carbon 2013, 51, 355-364. [CrossRef]

46. Badini, C.; Fino, P.; Ortona, A.; Amelio, C. High temperature oxidation of multilayered SiC processed by tape casting and sintering. J. Eur. Ceram. Soc. 2002, 22, 2071-2079. [CrossRef]

47. Wilhelm, M.; Wruss, W. Influence of annealing on the mechanical properties of SiC-Si composites with sub-micron SiC microstructures. J. Eur. Ceram. Soc. 2000, 20, 1205-1213. [CrossRef]

48. Xia, A.; Huizhao, Z.; Li, Y.; Chengshan, X. Formation of carbon nanowires by annealing silicon carbide films deposited by magnetron sputtering. Appl. Surf. Sci. 2002, 193, 87-91. [CrossRef] 
49. Yang, W.S.; Biamino, S.; Padovano, E.; Pavese, M.; Marchisio, S.; D’Amico, G.; Mio, S.C.; Chen, X.; Fino, P.; Badini, C. Thermophysical properties of $\mathrm{SiC}$ multilayer prepared by tape casting and pressureless sintering. Compos. Struct. 2013, 96, 469-475. [CrossRef]

50. Kuenle, M.; Janza, S.; Eibl, O.; Berthold, C.; Presser, V.; Nickel, K.-G. Thermal annealing of SiC thin films with varying stoichiometry. Mater. Sci. Eng. B 2009, 159-160, 355-360. [CrossRef]

51. Ferrari, A.C.; Robertson, J. Interpretation of Raman spectra of disordered and amorphous carbon. Phys. Phys. Rev. B 2000, 61, 14095-14107. [CrossRef]

(C) 2019 by the authors. Licensee MDPI, Basel, Switzerland. This article is an open access article distributed under the terms and conditions of the Creative Commons Attribution (CC BY) license (http:/ / creativecommons.org/licenses/by/4.0/). 